\title{
Novas mídias, mobilização transnacional e as reestruturações das esferas públicas*
}

\author{
Markus S. Schulz**
}

A difusão acelerada da Internet confere à questão do potencial democrático das novas tecnologias de comunicação interativas máxima importância e urgência. Interesse especial merece a influência da transformação das mídias sobre a orientação da comunidade e solidariedade, assim como a qualidade deliberativa da comunicação política. Essas questões serão abordadas a partir da perspectiva de uma pesquisa empírica sobre telecomunicação política relacionada a um conflito que ultrapassa fronteiras. É bem verdade que em muitos países a fase inicial de difusão da Internet no cotidiano ainda não está encerrada, contudo, já é possível obter experiências que podem enriquecer a discussão teórica e prática. Após a euforia inicial sobre o potencial democratizante e libertador da Internet, como uma mídia de uma sociedade mundial que se constitui, ceder lugar à desilusão cética, da mesma forma que a um temor apocalíptico do surgimento inevitável de um totalitarismo eletrônico, revela a necessidade de questionar sobre os possíveis impactos das novas mídias.

* Texto original em alemão traduzido por Hermílio Santos.

** Doutor em sociologia pela New School for Social Research, professor na University of Illinois e presidente do Research Committee 07 (Futures Research) da International Sociological Association - ISA.

Civitas

Porto Alegre

v. 7

ก. 2

jul.-dez. 2007

p. $108-128$ 


\section{Mídias e democracia}

Inicialmente, trata-se de localizar a questão em um contexto teórico geral. Os elementos decisivos da reflexão, esboçada brevemente a seguir, sobre a conexão entre mídia e democracia encontram-se em uma área de interseção transdisciplinar de filosofia política, ciências sociais e teoria das mídias. O significado de infra-estruturas das mídias para a existência de liberdade política já havia sido reconhecido por Tocqueville ([1835/1840] 1997) em seu clássico estudo "Sobre a democracia na América", quando ele afirmou que sob as condições de uma democracia de massas deveriam ser encontradas mídias que possibilitassem o intercâmbio de idéias dos cidadãos também através de longas distâncias. Diante da variedade de jornais da época, o problema da concentração da imprensa dificilmente poderia ser colocado.

A partir de sua análise da rede de telefonia, Flusser descreve o que está em jogo, na constituição dos caminhos de comunicação, por meio do desenvolvimento de dois cenários: ou o telefone servirá como modelo de comunicação em rede e com isso irá permitir uma "sociedade telemática de reconhecimento do outro e de auto-conhecimento no outro", ou as conexões seriam tão interligadas que disso surgiria uma "sociedade de massa programada e dirigida de maneira centralizada” (Flusser, ([1991] 1999, p. 191).

Arendt acentuou recorrentemente em suas obras que o poder se origina do entendimento e da ação conjunta. Ela colocava poder em contraposição direta à violência física, sobre a qual são construídas as tiranias (Arendt, ([1970] 1998). Caso os caminhos do entendimento entre os membros da sociedade estejam rompidos, fica impedida a formação do poder. Entretanto, em sua análise, uma tirania é sempre instável, uma vez que a todo momento novos caminhos de entendimento podem irromper e abalar a dominação da violência.

Mídias livres estão em contradição com regimes autoritários. A palavra livre pode conduzir ditaduras à derrocada. Contudo, a existência de mídia livre ainda não é suficiente para a estabilização e a construção da democracia, como está bastante claro no momento nos países pós-socialistas do leste europeu (Bennett, 1998). Para além da infra-estrutura das mídias, depende também de uma cultura política correspondente. Os fatores que conduzem a uma derrocada da esfera pública foram apontados por Habermas ([1962] 1990) em sua análise clássica sobre a mudança estrutural da esfera pública. O pressuposto para uma deliberação informada é o reconhecimento recíproco em uma comunicação interativa (Habermas, 1981). 
Como Dewey já havia postulado ([1927] 1984), as fronteiras da esfera pública não são fixas, mas ao contrário, relacionadas a problemas. Segue-se daí que não têm que coincidir de maneira alguma com as fronteiras dos estados nacionais hoje existentes. Na medida em que o Estado, segundo Dewey, é considerado apenas como um órgão executivo da esfera pública, suas fronteiras não são dadas em sua essência, senão que igualmente relacionadas a problemas. As possibilidades de reformulação da constituição política e para a auto-condução da sociedade ocorrem a partir da capacidade de percepção e da vitalidade de imaginação das esferas públicas constituídas espontaneamente. A efetividade destas esferas públicas estará limitada pela força das circunstâncias e pelo horizonte da imaginação social, em torno do qual é disputado na comunicação social (Calhoun, 1993; Cohen e Arato, 1992).

Problemas ambientais agudos, migrações de população provocadas por pobreza e crises, assim como um constante fluxo de notícias sobre acontecimentos em todo o mundo que faz com que o já antigo conceito de esfera pública mundial volte a estar na moda, não impedem de maneira alguma que novos conceitos de esfera pública mundial se tornem moda. Há alguns anos é discutido o surgimento de uma sociedade civil "internacional" (Kößler e Melber, 1993), "transnacional” (Bornschier, 1996) ou "global" (Hamelink, 1991; Lipschutz, 1992; Frederick, 1993a, 1993b). Não existe, contudo, qualquer consenso quanto à questão se a atual "desnacionalização" (Zürn, 1998) conduz a uma "cosmopolítica" de cidadãos mundiais ou a uma "aldeia global” (McLuhan e Powers, 1989) mais integrada. Entretanto, praticamente ninguém nega que as mídias, especialmente a Internet, assumem um significado central nesse processo. Na medida em que as mídias possibilitam a difusão de idéias e informações sobre outras formas de vida, elas permitem igualmente um julgamento distanciado do mundo da vida próprio, imediato de cada um, o que potencialmente pode motivar mudanças das condições de vida (Appadurai, 1996; Thompson, 1995). O fluxo de idéias políticas para além de fronteiras estabelecidas torna-se mais fácil. Grupos e indivíduos, para os quais o contato não era possível, encontram finalmente as possibilidades técnicas para isso. Por e-mail pode-se comunicar entre continentes com tanta facilidade ou dificuldade quanto com o vizinho da próxima casa. A diferença entre local e global se dissolve no ciberespaço das redes de computador. A distância espacial perde uma parte de seu significado. 
Por outro lado, já se projetou sobre o jornal como mídia de massa a esperança do entendimento pacífico entre os povos. Propaganda nacionalista e agitação de guerra frustraram a euforia. Ao invés de cosmopolitismo parece que as mídias impressas reforçaram a imaginação de pertencimento nacional, como mostra Anderson (1991). Na guerra, notícias tinham sempre um significado estratégico (Clausewitz, [1832] 1998). As esperanças projetadas hoje sobre a Internet poderiam se mostrar precipitadas, como aquelas projetadas para outras mídias. As discussões intrigantes sobre os efeitos das transformações das mídias sobre a política necessitam urgentemente de um enriquecimento por meio de pesquisas empíricas.

\section{Tecnologia, globalização e esfera pública}

É importante fazer uma breve exposição sobre a natureza das novas cibermídias, a fim de evitar confusões na avaliação da Internet. Vista de maneira mais detida, a Internet não é apenas uma mídia, mas muitas, uma multimídia, que oferece distintas funções comunicativas, ou uma hipermídia, que unifica em si estas possibilidades. E-mail, newsgroups, listas de endereços, Internet Relay Chat (IRC) e World Wide Web são as principais aplicações, em que, ao lado da simples comunicação por texto, cresce também a comunicação com audiovisual. Uma vez que ao lado da Internet existe uma variedade de Intranets, às quais apenas os funcionários das respectivas empresas têm acesso (Sassen, 1997), prefiro o conceito mais amplo de ciberespaço ao invés de espaço comunicativo cibernético, que se constitui a partir da formação de redes de computadores. ${ }^{1}$

A característica mais destacada da comunicação em rede é a tendência de descolamento do espaço físico, no sentido de que para o usuário não faz diferença se o interlocutor mora na casa vizinha do outro lado da rua ou do outro lado do mundo. No ciberespaço das redes de computador esmaece a diferença entre local e global. A distância espacial perde uma parte do seu significado.

1 A palavra "Ciberespaço” foi inventada pelo autor de ficção científica William Gibson, que a tornou popular em seu romance Neuromancer (Gibson, 1984). 
É indispensável considerar, contudo, a distribuição desigual do acesso à Internet. Apenas aqueles que possuem um acesso à Internet podem participar da comunicação cibernética, sobretudo aqueles que moram nos países industrializados e as classes mais altas dos países emergentes e em desenvolvimento (Behmer e Trapp, 2000; Donges, Jarren e Schatz, 1999; UNDP, 1999). É concebível que o preço para o acesso à Internet caia com a produção em massa dos equipamentos necessários e que aumente, assim, o número de participantes e, possivelmente, em um tempo relativamente curto, ocorra uma difusão semelhante à rede de energia (Geser, 1998). ${ }^{2}$

Contudo, somente a disponibilidade de infra-estrutura técnica não constitui comunicação efetiva. Enquanto a Hypertext Mark-up Language (HTML) possibilita a cooperação dos computadores, os usuários - a fim de se entenderem têm que dominar uma língua comum, que em geral é o inglês. A realização de atos de entendimento pressupõe interesses e vontades correspondentes. Um email pode ser eliminado antes de ser lido, assim como uma carta sempre pôde ser jogada fora sem ter sido lida. Em sentido semelhante, páginas da web podem da mesma forma ser lidas superficialmente ou folheadas como páginas de jornal. A demanda por possibilidades específicas de comunicação necessita somar-se às descobertas técnicas, afim de que uma infra-estrutura de mídia correspondente possa se difundir. A cultura social das mídias e a constituição técnica das mídias caminham lado a lado. Nesse sentido, a globalização sócioeconômica e o desenvolvimento da Internet transcorrem simultaneamente e, com isso, beneficiam-se reciprocamente.

Porém, na medida em que a globalização econômica avança, surgem exigências de regulações políticas globais. Assim como no âmbito nacional, diante da autonomização autoritária ou ditatorial, o sistema de condução política apenas pode ser preservado por uma esfera pública eficiente. Estruturas ativas da sociedade civil, enquanto contrapeso democrático, dificilmente são dispensáveis também em nível global. Desta maneira coloca-se a questão de qual formato elas assumem no contexto das novas mídias e quais as possibilidades de influência elas podem oferecer.

2 De acordo com a International Telecommunication Union haviam até final do ano de 2004 aproximadamente 840 milhões de usuários de Internet em todo o mundo, ou seja, em torno de $13 \%$ da população mundial tinha acesso à rede, sendo que o percentual de acesso na Europa e na América do Norte era consideravelmente mais alto que na América Latina ou África (ITU, 2006; Schulz, 2007). 


\section{Realidade empírica da cibersociedade}

Dificilmente irá se dar uma esfera pública unitária ou integrada entre os milhões ou, em breve, bilhões de participantes da hipermídia Internet (ou suas sucessoras, mescladas com outras mídias eletrônicas). É muito mais plausível a tendência de se formarem esferas públicas globalizadas no plural. Distâncias e fronteiras puramente geográficas perdem importância relativa. Os limites mais importantes são os da língua, das visões de mundo e dos estilos de vida. A esfera pública da comunicação mediada por computador exibe uma estrutura do tipo rede. As redes de cabos da Internet demonstram isso. Nessa perspectiva, torna-se perceptível que a esfera pública, vista como uma estrutura de rede complexa, na verdade, sempre se apresenta no plural. Esferas públicas são dinâmicas, distintamente ativas e distintamente eficazes, assim como envolvidas constantemente em processos de desintegração e de ressurgimento. A questão se a esfera pública está desintegrada, se desitegra ou se irá se desintegrar deveria, portanto, ser separada da questão de como esferas públicas constantemente se desintegram e se formam novamente, ou seja, como esferas públicas, como arenas principais e secundárias, sempre se transfiguram ao longo do tempo.

Na Internet, a comunicação política constitui apenas uma parte relativamente pequena da sua comunicação. Para o intercâmbio de idéias e a coordenação de atividades sobre temas como direitos humanos, meio ambiente e resolução de conflitos ela possui, entretanto, um significado considerável.

Regimes autoritários vêem a difusão da Internet de maneira discrepante. As possibilidades comerciais são altamente desejadas, porém, a perda de controle é considerada uma ameaça. No Iraque e na Síria a questão da Internet ainda é analisada. Na Arábia Saudita existe acesso à Internet apenas desde janeiro de 1999. Todas as conexões são conduzidas a um distribuidor central em Riad, de onde o acesso a páginas que não são consideradas de acordo com a religião e a sociedade é bloqueado, e assim são detectadas por uma lista de proibições ampliada diariamente (Jehl, 1999). Na República Popular da China há esforços semelhantes. Um atalho continua disponível: a Internet via ligação telefônica ao exterior, o que pode ser bastante caro.

As novas tecnologias de comunicação ajudam a superar fronteiras e, com isso, desafiam a soberania estatal. Movimentos de resistência e críticos do 
regime podem, com a ajuda da Internet, contornar a censura ou escapar da perseguição e da repressão, sem ter que abandonar as atividades de publicidade. Existem exemplos disso em todo o mundo. Separatistas curdos, tâmiles e do sahara ocidental, assim como grupos de guerrilha mexicanos e peruanos, não apenas imprimem jornais, brochuras e panfletos, mas fazem uso intenso também da Internet. Na Alemanha, a Agência Federal para a Proteção da Constituição (Bundesamt für Verfassungsschutz, 1998) se ocupa das atividades de Internet da extrema direita. Escritos nazistas e símbolos que são proibidos na Alemanha são distribuídos, por exemplo, a partir do Canadá. A Internet ajuda na produção de contra-esferas públicas e oferece oportunidade para a própria representação, para fugir da censura, perseguição e discriminação. Em princípio, essas possibilidades podem ser utilizadas tanto pelos apoiadores quanto pelos opositores de concepções democráticas e de liberdade.

A pesquisa empírica das novas ciberesferas públicas é uma tarefa altamente complexa, que exige uma limitação do método. A seguir quero analisar um caso relativamente claro de conflito de comunicação transnacional, que parece ser instrutivo para a compreensão da estrutura, dinâmica e impacto de esferas públicas telecomunicativas.

\section{Rebelião em Chiapas}

Para um estudo de caso explorativo, o levante dos zapatistas é bastante apropriado, uma vez que aqui distintos tipos de esfera pública do centro e da periferia estão articulados de maneira efetiva. ${ }^{3} \mathrm{O}$ levante armado de cerca de 3.000 agricultores indígenas no estado de Chiapas, no sudeste mexicano, tornou-se um acontecimento de mídia em todo o mundo. O Exército Zapatista de Libertação Nacional (EZLN), como o grupo rebelde se tornou conhecido, ocupou diversas cidades, entre elas também San Cristóbal de las Casas, importante para o turismo internacional, e protestou "contra a exploração e opressão” que, nas suas palavras, eles têm suportado desde a colonização até o regime de dominação ininterrupta de um único partido, conduzido ao longo de setenta anos pelo Partido da Revolução Institucional (PRI). O Acordo de Livre-comércio Norte-americado (NAFTA), que entrou em vigor simultaneamente ao levante, em $1^{\circ}$ de janeiro de 1994, foi caracterizado por eles como

3 Para as causas e bastidores do levante, ver Schulz (1998 e 2000). 
uma "pena de morte para os indígenas”. O governo mexicano reagiu imediatamente ao levante com o envio de tropas federais. Após doze dias de lutas, o Presidente Carlos Salinas anunciou, contudo, um cessar-fogo e o início de negociações. Como isso ocorreu? Os zapatistas, em parte armados apenas com rifles de madeira, teriam poucas chances em um conflito militar direto contra o exército federal, que contava com dezenas de milhares de soldados e armamento pesado, aviões e helicópteros. Os zapatistas, por sua vez, já haviam tentado a fuga para a floresta tropical da Lacandona, em montanhas de difícil acesso, quando foram atacados na retaguarda. Não foram motivos militares, mas políticos, que influenciaram a interrupção da ofensiva governamental. Na decisão de interromper a guerra, o governo se viu confrontado com um enorme interesse da mídia e com protestos nacionais e internacionais, e teve que ponderar que uma guerra longa e suja seria danosa não apenas para as ambições que Salinas mantinha em presidir a Organização Mundial do Comércio (OMC), mas seria também arriscado para a economia mexicana, altamente dependente dos humores do mercado mundial, e para o regime dividido e desafiado em sua legitimação, que em breve teria que se submeter às eleições. A partir dessas reflexões segue que o fator esfera pública foi de grande significado para o desenvolvimento do levante zapatista e, por essa razão, merece uma análise mais detida.

Por que o levante zapatista se tornou um acontecimento mundial de mídia? Diversas razões parecem se encontrar aqui. Inicialmente, o México é um país vizinho sobre o qual a mídia norte-america informa com regularidade na seção de exterior, baseado no critério jornalístico de notícia "proximidade geográfica”. Devido à controvérsia em torno do NAFTA havia uma atenção adicional sobre o México. Com relação ao NAFTA haviam sido antecipadas as mais distintas conseqüências. Um levante guerrilheiro exatamente no dia em que passou a vigorar surgiu, contudo, como uma enorme surpresa. O debate sobre o NAFTA ganhou assim combustível adicional. No início do levante não havia clareza quanto à sua real dimensão. Logo chegaram ao noticiário dramáticas imagens de guerrilheiros mascarados em paisagem de florestas com neblina e soldados fortemente armados diante de mulheres indígenas.

Importante não era apenas o que se informava sobre Chiapas, mas como isso era feito. No início do levante a maioria da mídia mexicana - que seguia a linha do governo - apresentava o EZLN como um "bando de criminosos" coordenados por "estrangeiros”. As mídias de massa mexicanas não estão 
submetidas à censura, mas em sua maioria são obedientes ao Estado e ao partido do governo. A difusão de outras visões dependia, por conseguinte, de contra-esferas públicas, da impressa alternativa, da mídia internacional e da comunicação na Internet. A articulação estreita de distintos tipos de esferas públicas possibilitou a difusão transnacional acelerada de notícias que desacreditavam as operações das tropas federais e davam amplo espaço às demandas e visões dos rebeldes.

Desde meados dos anos 1980 a sociedade civil mexicana se fortaleceu e começou a redefinir sua relação com o Estado. Irrompeu uma onda de formação de organizações não-governamentais (ONGs), especialmente organizações de direitos humanos, iniciativas de vizinhos e grupos indígenas. Para o fluxo de informação sobre os acontecimentos em Chiapas foi útil que os movimentos de democratização do campo e da cidade não estavam isolados uns dos outros, senão que estavam vinculados por meio de inúmeras relações pessoais e organizacionais, através das quais se pôde comunicar, mobilizar e coordenar. Dessa maneira, as informações sobre desrespeitos aos direitos humanos pelo exército federal, pronunciamentos importantes dos zapatistas e notícias a partir da perspectiva dos zapatistas foram difundidas primeiro através das redes de diferentes ONGs, em que o telefone, fax e Internet exerceram um importante papel. Um grande público foi alcançado por intermédio do jornal local El Tiempo (San Cristóbal de las Casas), o jornal regional La Jornada (Cidade do México) e, por fim, por meio da mídia de massa internacional.

O levante zapatista não foi recebido apenas com atenção e interesse, mas provocou também solidariedades e mobilizações. Na Cidade do México, assim como em diversas outras grandes cidades mexicanas, ocorreram grandes manifestações de protesto. Na capital mexicana reuniram-se na Zócalo, a praça central em frente ao palácio do governo, cerca de 100.000 pessoas. Também no exterior ocorreram grandes e pequenas demonstrações de solidariedade, especialmente nos Estados Unidos, Canadá, Itália, Espanha, França, Inglaterra, Alemanha e na Suíça.

Como se pode explicar a dimensão dessa mobilização transnacional? A difusão de informações sobre os acontecimentos em Chiapas foi uma précondição. Porém, o fluxo de informação não explica ainda a mobilização. Teve que apresentar-se uma indignação moral espontânea, uma ampla solida- 
riedade motivadora e a perspectiva de um mínimo de efetividade. A perspectiva de efetividade resultava da redução de legitimidade do regime do PRI após as fortes acusações de manipulação nas eleições presidenciais de 1988, do fortalecimento da sociedade civil mexicana e da crescente orientação ao exterior por meio do NAFTA.

\section{Mobilização e solidariedade}

A questão sobre as razões da solidariedade exige uma abordagem mais precisa da comunicação no interior das contra-esferas públicas da sociedade civil. Como os zapatistas conseguiram ganhar tantos simpatizantes e apoiadores dentro e fora do México? Como ocorreu esta aliança inusitada entre agricultores maias, moradores das cidades mexicanas e habitantes de países industriais e pós-industriais distantes que não falam espanhol? À primeira vista é bastante improvável uma aliança entre esses tipos de mundos tão distintos. Onde estaria a identidade comum ou, pelo menos, um interesse comum que poderia motivar os apoiadores de ações de solidariedade, a despeito das distâncias espaciais e culturais? Foi uma transformação romântica de uma cultura Maia exótica ou o desejo de aventura em uma paisagem monótona de bemestar (Luhmann, 1996)? As esquerdas procuravam pela substituição do sujeito revolucionário histórico perdido (Newsweek)? Foi uma hábil jogada de marketing da parte do subcomandante Marcos, um sociólogo e comunicólogo formado nas universidades do México e em Paris? (Grange e Rico, 1997)? Ou o velho sonho de justiça social (Castells, 1996)? Todos esses aspectos podem ter exercido um papel. Dado que nenhum outro grupo guerrilheiro do chamado "Terceiro Mundo" recebeu apoio nessas proporções, a combinação dos fatores deve ter sido decisiva.

Na transposição do discurso cultural, o subcomandante Marcos exerceu um papel decisivo de intermediação. Desde 1983 ele se familiarizou com a forma de vida dos indígenas de Chiapas e, por essa razão, estava em condições de exercer esse papel de tradução, importante para combinar essas distintas esferas públicas.

As demandas centrais dos zapatistas por justiça social, diálogo social sobre os objetivos do desenvolvimento e eleições livres foram consideradas bastante moderadas e justas. Em seus métodos, os zapatistas se distinguem 
visivelmente dos grupos maoistas e guevaristas, que por meios terroristas buscam assumir o poder para si, mas que fracassam na maioria das vezes. Parece que os zapatistas aprenderam com a história. Além disso, seus pronunciamentos estavam em sintonia fina com o discurso dos movimentos e grupos de esquerda após o fim da guerra fria. A suposição de que uma sociedade livre pudesse ser construída pelo atalho de uma ditadura estatal perdeu seu poder de atração. Não apenas capitalismo sem limites, como também autoritarismo político foram considerados como obstáculos para a construção de uma sociedade melhor. No centro dos esforços de democratização surgiu a idéia da sociedade civil ativa, concebida crescentemente como global.

Iniciativas zapatistas, como as Consultas Nacional e Internacional (verão de 1995), o Fórum Indígena Nacional (janeiro de 1996), o Encontro Continental (verão de 1995) e Intercontinental contra o Neoliberalismo e pelos Direitos Humanos (julho-agosto de 1996 e julho-agosto de 1997), a Marcha até a Cidade do México (setembro de 1997) e os esforços por uma rede de comunicação e resistência intercontinental (desde verão de 1996), intensificaram a solidariedade transnacional e mantiveram alerta a atenção pública.

As conexões com indivíduos, grupos e organizações em dezenas de países ajudaram a realizar estas e outras campanhas. Dessa forma, o trabalho de solidariedade na cidade de Nova York foi organizado por grupos como o Committee for Democracy in Mexico. Suas atividades compreendem eventos de informação, demonstrações diante do consulado mexicano local, festas na comemoração de aniversário do levante, exposições, apresentação de vídeos e concertos beneficentes. Assim como todo o grupo, a composição de seu núcleo mais ativo era heterogênea e flutuante. O número de mulheres era aproximadamente o mesmo que de homens, assim como haviam tantos americanos brancos quanto latinos e indígenas. Alguns dos membros eram estudantes, outros exerciam profissões liberais diversas. A faixa de idade ia desde adolescentes até a idade de aposentados. Diversos membros eram ativistas políticos experientes, que já haviam se engajado antes em temas políticos e internacionais. Outros decidiram pela primeira vez se engajar, seja porque tinham algum vínculo pessoal com o México ou simplesmente porque se sentiam compelidos a participar em algo que consideravam válido. 
Grupos europeus de solidariedade realizaram entre 26 de julho e 3 de agosto de 1997, na Espanha, o Segundo Encontro Intercontinental. Dentre os grupos de apoio europeus mais ativos estavam o Réseau Solidarité Mexique em Paris; Solidaridad Directa e o Mexiko-Gruppe em Berlim, Penumbra em Frankfurt, o Centro Felix Varela em Rüsselsheim; o Amsterdam Solidarity Committee na Holanda; o Comitato Chiapas di Torino, o Coordinamento Zapatista per l'Italia, La Strada e a Tactical Media Crew, na Itália; o Colectivo Zapatista de Granada e a Plataforma de Solidaridad con Chiapas de Aragón, na Espanha, assim como o Solidaridad Directa con Chiapas, em Zurique. Somente nos países de língua alemã puderam ser contabilizados 39 grupos de solidariedade (REDaktion, 1997).

Os diferentes grupos de solidariedade não criaram qualquer organização central, mas estabeleceram redes horizontais por meio das telecomunicações em torno a temas ocasionais. A Internet possibilitou aos zapatistas divulgar suas mensagens a um público mundial e, com isso, ganhar apoio nacional e internacional. Por correio eletrônico foi convocada, por exemplo, a "mobilização internacional geral”, que se realizou em 16 de fevereiro de 1997 - aniversário da assinatura do Acordo de San Andrés - simultaneamente em diversas cidades européias, australianas e americanas, dentre elas 30 cidades norteamericanas (Bellinghausen, 1997). Na verdade, os zapatistas, em seu esconderijo da floresta de Lacandona, não dispõem de uma conexão própria de Internet, mas apoiadores no México e nos países industrializados enviam seus documentos por e-mail para grupos eletrônicos de notícias, como por exemplo o Chiapas95 e Mexico2000, e mantém páginas de Internet especiais em nome dos zapatistas.

\section{Conflito no ciberespaço}

Na Internet é possível encontrar uma dúzia de endereços especialmente dedicados à rebelião zapatista (cf. Cleaver, 1996 para a mais extensa lista de endereços de Internet). Para dar um exemplo, um dos sítios zapatistas www.ezln.org - foi construído por um voluntário na primavera de 1994 com autorização do EZLN (Paulson, 1997). Hoje esse sítio é mantido por Virtual Sites, uma afiliada da empresa de consultoria em engenharia de Internet GW Communications, sediada em San Franciso (Virtual Sites, 1997). Originalmente o objetivo do sítio era colocar à disposição nos Estados Unidos traduções de documentos do EZLN. Dado que o sítio foi utilizado também dentro do México 
e em outros lugares, desde 1995 decidiu-se tornar o material disponível tanto em inglês quanto em espanhol e, de vez em quando, até mesmo em alemão. Desde a instalação de contador de visitas em outubro de 1996, o sítio foi visitado até 21 de janeiro de 2000 exatamente 725.000 vezes, o que perfaz uma média de 18.000 visitas por mês. ${ }^{4}$

O papel exercido pela Internet no conflito de Chiapas não deveria ser nem superestimado nem subestimado. Em um estudo para o Pentágono, Ronfeldt e Arquilla (1998) caracterizaram o tipo da utilização da Internet no conflito de Chiapas como o protótipo de uma nova forma de condução de guerra, o "social netwar” ("guerra social na rede”). Cleaver (1995) falou de uma "new electronic fabric of struggle” (“nova fábrica eletrônica de luta”). Em contraposição a isso, Teuthorn (1999) argumentou que pela Internet de fato não se pôde alcançar um grande público, mas que ao final das contas exerceu influência sobre o governo mexicano, precisamente na medida em que este superestimou as opiniões ali publicadas. Em junho de 1996 havia no México estimados 100.000 usuários de Internet, com tendência de crescimento (Carson, 1996). Contudo, qual mídia exerceu que influência sobre as decisões concretas do governo dificilmente pode ser determinada. Certo é que a maior parte da opinião pública foi alcançada pela televisão, rádio e mídia impressa, enquanto as demonstrações de massa na praça Zócalo, na capital, como extraordinária tomada de posição de amplos segmentos da população, representaram o meio de pressão mais visível.

Nos primeiros anos do conflito parecia que a causa dos zapatistas estava muito melhor representada que aquelas do governo mexicano, graças ao apoio voluntário na Internet. Ultimamente, porém, o governo se recuperou nessa área e oferece diversos e coloridos sítios na Internet em espanhol e em inglês, que contêm arquivos de declarações à imprensa, projetos de lei, discursos do presidente, fotos e vídeos (http://www.presidencia.gob.mx). Na página inicial se faz referência especial a acontecimentos atuais. Colocam à disposição páginas especiais para crianças. Sobre o tema Chiapas há uma extensa seção especial. À pedido, são encaminhados regularmente por e-mail notas de imprensa aos assinantes. Também o governo estadual de Chiapas possui nesse interim sua própria página na Internet (http://www.chiapas.gob.mx), que de acordo com os dados do contador de visitas, instalado há um ano, recebeu 37.000 visitas.

4 Na avaliação do número de visitas às páginas de Internet deve-se considerar que ela não informa quantos visitantes diferentes entraram na página. 


\section{Dinâmica da comunicação de listas de correio eletrônico}

Os dois grupos de notícias mais importantes sobre a rebelião zapatista são Chiapas-L e Chiapas95. ${ }^{5}$ Desde o seu início, no final de 1994, foram encaminhados por cada um dos dois grupos, sediados no sul do Estados Unidos, cerca de 20.000 diferentes mensagens. ${ }^{6}$ As mensagens serviram basicamente para o fornecimento de informações para todo o mundo sobre os acontecimentos em Chiapas e em torno de Chiapas, e eram em geral escritos em inglês ou em espanhol. Chiapas95 surgiu a partir da iniciativa de Harry Cleaver, desde os anos 1970 professor de economia marxista na Universidade do Texas, em Austin, e é mantido pelo grupo de solidariedade Accion Zapatista. Chiapas-L foi criado por um grupo de estudantes da Universidade da Califórnia, em San Diego.

Em uma primeira avaliação do conjunto de mensagens de ambas as listas, ${ }^{7}$ quase dois terços reproduzem os conteúdos de agências de notícias ou de outras mídias, por exemplo do jornal mexicano La Jornada. Cerca da metade do terço restante se ocupa de campanhas. Fazem parte avisos de campanhas, convocação para manifestações, esboço de cartas de protesto e detalhes sobre campanhas em andamento. Cerca de um sexto das mensagens consistem em análises, avaliações e contribuições ao debate.

Uma vez que as mensagens são encaminhados em geral a diversas sublistas, é difícil calcular o número exato de leitores ou de assinantes. Além disso, varia bastante o número e os nomes dos assinantes. No verão de 1999, Chiapas-L contava com 177 assinantes (contagem de 5 de julho de 1999) e Chiapas95 contava com 312 assinantes (contagem de 3 de julho de 1999). A

5 A análise das listas eletrônicas de correio resulta de um estudo realizado na Faculdade de Comunicação da Bauhaus-Universität sobre "Transformação do espaço público através das novas mídias”. Agradeço a Angela Richter pelo apoio ativo como assistente de pesquisa.

6 Às vezes as listas se sobrepõem, uma vez que não é raro que a mesma mensagem seja enviada por ambas as listas.

7 Em razão da ampla automatização no envio, ocorre que não raramente são colocadas mensagens em circulação que possuem como conteúdo apenas um comando de "cancelamento", não possuem qualquer conteúdo ou apenas o texto que reproduz uma mensagem já encaminhada sem acrescentar nada novo. Na análise, porém, foram consideradas apenas mensagens com conteúdo significativo. Contudo, incluiu-se também, após uma definição mais ampla, mensagens que contém apenas siglas, consideradas como uma intenção de comunicação e não como um defeito técnico. 
julgar pelo volume de comunicação, os assinantes permanentes de Chiapas-L e Chiapas-95 devem ter desenvolvido um interesse considerável sobre Chiapas. Pode-se assumir que a esses grupos pertencem os ativistas e multiplicadores mais ativos. Considerando os endereços de e-mail dos assinantes de Chiapas-L no dia da contagem, a maior parte (84\%) era de países do mundo (pós)industrial (América do Norte, Europa, Austrália, Japão), em que instituições de ensino norte-americano respondem por dois terços dos endereços. Doze por cento era do México, outros dois por cento de outros países latinoamericanos. Não estavam representados países em desenvolvimento que não eram latino-americanos.

A partir de um cálculo baseado em uma amostra aleatória ( $\mathrm{N}=119)$, cerca da metade dos e-mails identificados era de remetentes com um endereço norte-americado ou canadense. Um terço das mensagens enviadas e classificadas vinha de remetentes mexicanos. O restante provinha de países latinoamericanos (4\%) e europeus (11\%), especialmente da Espanha (5\%).

O Gráfico 1 traz o número de e-mails que se comunicaram em ambas as listas. Ele mostra uma continuidade considerável na frequência de comunicação, que ao longo dos anos permaneceu igual em ambas as listas. O gráfico deixa claro que não se trata de um tema da moda, sobre o qual se comunicou por um curto período de tempo e que cessou após um pico de interesse inicial.

Gráfico 1: Volume de comunicação anual

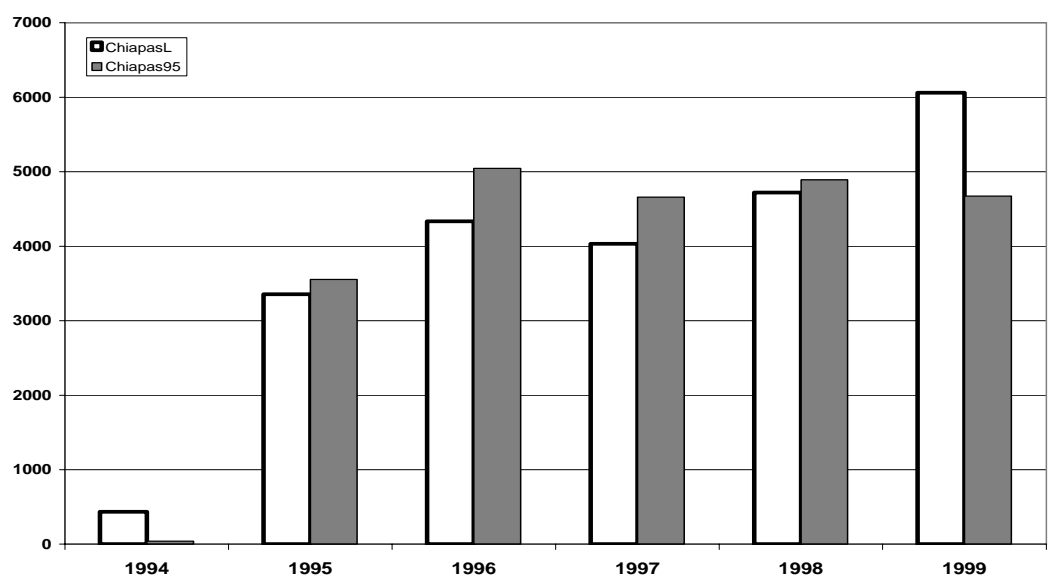


O Gráfico 2 mostra a média mensal da frequência de comunicação na lista Chiapas-L. Os altos e baixos da curva transmitem uma impressão da conjuntura de comunicação e recuos na comunicação. Do que depende a intensidade da comunicação? Dos acontecimentos em Chiapas mesmo ou do calendário externo dos ativistas internacionais? Uma resposta obtem-se da comparação do traçado do gráfico com a cronologia dos acontecimentos no contexto do levante. Alguns exemplos ilustram isso.

Gráfico 2: Modelos de freqüência de comunicação mensais

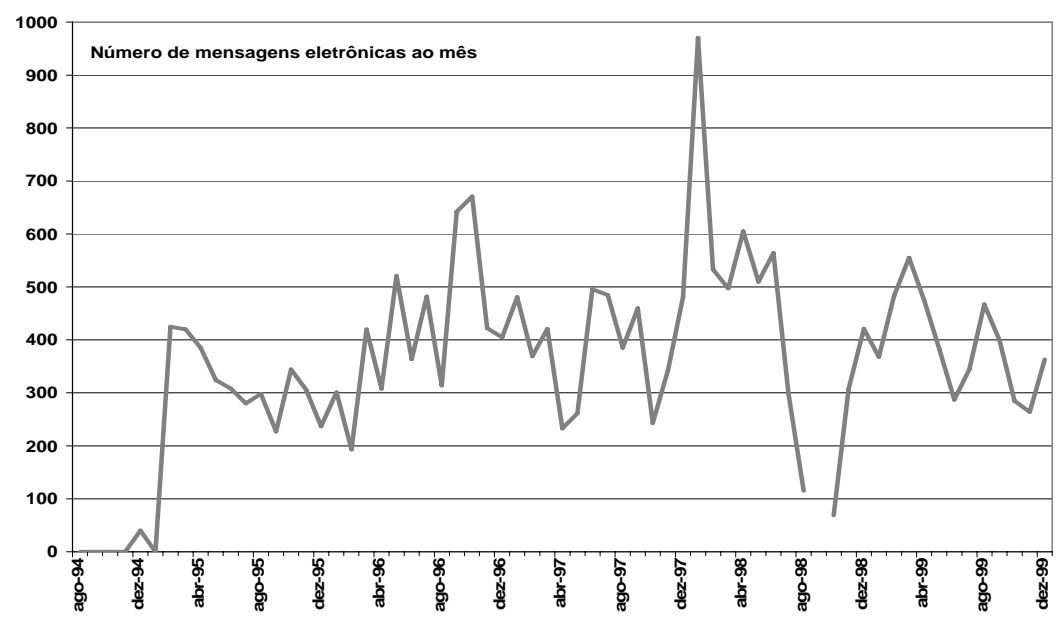

A freqüência de comunicação foi especialmente alta em fevereiro de 1995. Isso corresponde à segunda maior contra-ofensiva do governo mexicano, após a qual sucederam-se protestos internacionais, que levaram a interrupção da ação militar. Um outro ponto alto na comunicação aconteceu em agosto de 1996. Nesse período ocorreu em Chiapas o "Encontro Intercontinental contra o Neoliberalismo e pelos Direitos Humanos”. O ponto mais alto da curva corresponde a dezembro de 1997 e pode-se atribuir ao massacre de Acteal, no qual 45 moradores de vilarejos pro-zapatistas foram mortos e em conseqüência do qual ocorreu uma onda de ações de solidariedade.

Na parte da curva que corresponde ao mês de setembro de 1998 de Chiapas95 ocorre uma lacuna visível. Nesse período não foram enviados quaisquer mensagens, uma vez que a lista estava temporariamente dissolvida. Os 
operadores iniciais se viram sem tempo para colocar a lista em funcionamento. Depois que isso se tornou conhecido, encontrou-se rapidamente um novo grupo de voluntários que ocuparam seus lugares e assumiram a coordenação da lista.

Os exemplos mencionados permitem definir a dinâmica do desenvolvimento das curvas de comunicação como produto dos acontecimentos em Chiapas e dos acontecimentos nos grupos de ativistas internacionais. ${ }^{8} \mathrm{O}$ fluxo contínuo de informação ajudou a manter conexões latentes, que, quando necessário, puderam ser ativadas rapidamente.

Uma primeira avaliação das linhas de discussões temáticas destas listas, assim como de outras sublistas sobre o levante zapatista, demonstra que as características estruturais da comunicação das mídias de massa se repetem também na Internet. Relações de comunicação assimétrica, falta de disposição para a argumentação e falhas na profundidade de informação surgem aqui também como problema. As tecnologias de telecomunicação interativas colocam à disposição dos atores sociais inúmeros canais de nichos de deliberação, mas elas não garantem um discurso livre de dominação.

\section{Conclusão}

O estudo de caso mostrou, de maneira exemplar, como diferentes tipos de esferas públicas podem estar articuladas de maneira eficiente e qual papel as novas tecnologias de telecomunicação interativas são capazes de exercer no estabelecimento de redes de atores locais. Enquanto os zapatistas tinham acesso a redes pessoais, organizacionais e informacionais, foi possível a eles ganhar apoiadores de setores heterogêneos da sociedade civil. A sobrevivência dos zapatistas foi facilitada pelo fato de que eles operavam a partir de uma região quase inacessível, que o exército mexicano dificilmente poderia controlar sem uma grande campanha maciça. Uma tal campanha parece improvável, tendo em vista o enorme interesse da mídia e o amplo apoio que gozam os zapatistas no México e no exterior. Quando o exército tentou vencer violentamente os zapatistas, imediatamente após o levante, e novamente

8 Em razão do espaço, uma discussão sobre frequência da comunicação diária deve ficar para outra ocasião. A avaliação mensal tem a vantagem de poder desconsiderar problemas técnicos, como defeito do servidor. 
durante a segunda grande ofensiva em fevereiro de 1995, o protesto nacional e internacional foi tão intenso que o governo encerrou a ação militar e se esforçou nas negociações por uma solução pacífica. O NAFTA integrou o México ao mercado mundial de maneira ainda mais forte e permitiu ao governo mexicano criar uma imagem para si favorável a investimentos. Uma guerra suja demorada poderia se mostrar demasiadamente cara, tanto política como economicamente. A luta dos zapatistas tornou-se, por isso, crescentemente uma luta de palavras, graças às esferas públicas transnacionais. Com iniciativas, como a consulta nacional e intercontinental e encontros, os zapatistas mantiveram não apenas a atenção da opinião pública voltada para eles, como também garantiram para si a solidariedade de amplos movimentos. As iniciativas transnacionais foram um fator decisivo para a sobrevivência dos zapatistas e atuaram ao mesmo tempo como um catalisador na formação de uma esfera pública transnacional, que se engajou na discussão em torno aos problemas políticos do período.

A qualidade comunicativa das deliberações não é determinada pela infraestrutura das mídias. Ela depende da disposição dos atores sociais para o reconhecimento recíproco. Por meio do reconhecimento as esferas públicas podem sempre se reconstituir. Através de limitações e exclusões elas se fragmentam e se desintegram. As estruturas das esferas públicas estão, nesse sentido, sempre em movimento. E a extensão a que estas esferas públicas sempre em mudança podem se tornar eficazes e desenvolvem seu potencial democrático, depende, em grande medida, da criatividade dos atores sociais envolvidos.

\section{Referências}

ANDERSON, Benedict. Imagined Communities: Reflections on the Origins and Spread of Nationalism, New York: Verso, 1991.

APPADURAI, Arjun. Modernity at Large: Cultural Dimensions of Globalization, Minneapolis: University of Minnesota Press, 1996.

ARENDT, Hannah. Über Macht und Gewalt, München: Pieper, 1969.

BEHMER, Markus; TRAPP, Bettina. More Connected? Neue Medien und 'Eine Welt' - Chancen und Risiken. In: BROSIUS, Hans-Bernd (Org.). Kommunikation über Grenzen und Kulturen. Konstanz: UVK, 2000. 
BENNETT, W. Lawrence. The Media and Democratic Development. In: O’NEIL, Patrick H. (Org.). Communicating Democracy: The Media and Political Transitions, Boulder/London: Lynne Rienner, 1998.

BELLINGHAUSEN, Hermann. El domingo, movilización internacional en apoyo a Zapatistas, La Jornada, 15.02.1997, distribuído por Amancer Press aos múltiplos receptores da lista eletrônica Mexico2000, 15.02.1997.

BORNSCHIER, Volker. Zivilisierung der Weltgesellschaft trotz Hegemonie der Marktgesellschaft?. Zürich: Universität Zürich, 1996.

Bundesamt für Verfassungsschutz. Right-Wing Extremist Activities, 1998. In: Internet, <http://www.verfassungsschutz.de/reinteng.htm> [acessado em 11.10.1998].

CALHOUN, Craig. Civil Society and the Public Sphere, Public Culture, n. 5, 1993, p. 267-280.

CARSON, Teresa. Internet's Popularity Leaping in Latin America, Miami: Reuters, 26.06.1996.

CASTELLS, Manuel. The Information Age: Economy, Society and Culture, Bd. 1: The Rise of the Network Society, Cambridge, MA: Blackwell, 1996.

CLAUSEWITZ, Carl von. Vom Kriege. Stuttgart: Reclam, ([1832] 1998).

CLEAVER, Harry. The Zapatistas and the Electronic Fabric of Struggle, 1995. <http://www.eco.utexas.edu/faculty/Cleaver/zaps.html> [acessado em 13.11. 1997].

CLEAVER, Harry. Zapatistas in Cyberspace: A Guide to Analysis \& Resources, 1996. <http://www.eco.utexas.edu/faculty/Cleaver/zapsincyber.html> [acessado em 13.11.1997].

COHEN, Jean; ARATO, Andrew. Civil Society and Political Theory, Cambridge, MA: MIT Press, 1992.

DEWEY, John. The Public and Its Problems, The Later Works, V. 2, Carbondale: Southern Illinois University Press, ([1927] 1984).

DONGES, Patrick; JARREN, Otfried; SCHATZ, Heribert (Orgs.). Globalisierung der Medien: Medienpolitik in der Informationsgesellschaft, Opladen: Westdeutscher Verlag, 1999.

FLUSSER, Vilém. Die Geste des Telefonierens. In: PIAS, Claus; VOGL, Joseph; ENGELL, Lorenz; FAHLE, Oliver; NEITZEl, Britta (Orgs.). Kursbuch Medienkultur, Stuttgart: DVA, ([1991] 1999).

FREDERICK, Howard H. North American NGO Computer Networking on Trade and Immigration: Computer Comunications in Cross-Border Coalition Building, Santa Monica: RAND, Paper DRU-234-FF, 1993a. 
FREDERICK, Howard. Computer Networks and the Emergence of Global Civil Society. In: HARASIM, Linda M. (Org.). Global Networks: Computers and International Communication, Cambridge, MA: MIT Press, 1993b.

GRANGE, Bertand de la; RICO, Maite. Marcos, la genial impostura, México: Aguilar, 1997.

GESER, Hans. Die Neuerfindung der politischen Öffentlichkeit: Das Internet als selbstevolutive Plattform der Medienentwicklung und des sozio-politischen Wandels, 1998. <http://www.socio.ch/sim/kopf/htm> [acessado em 29.02.2000].

GIBSON, William. Neuromancer, New York: Ace Books, 1984.

HABERMAS, Jürgen. Strukturwandel der Öffentlichkeit: Untersuchungen zu einer Kategorie der bürgerlichen Gesellschaft, Frankfurt am Main: Suhrkamp, ([1962] 1990).

HABERMAS, Jürgen. Theorie des kommunikativen Handelns, 2 Bde., Frankfurt am Main: Suhrkamp, ([1981] 1988).

HAMELINK, Cees J. Global Communication: Plea for Civil Action. In: HOFSTEN, B. V. (Org.). Informatics in Food and Nutrition, Stockholm: Royal Academy of Sciences, 1991.

HERZOG, Roman; HOFFMANN, Bert ; SCHULZ, Markus S. Internet und Politik in Lateinamerika: Regulierung und Nutzung der Neuen Informationstechnologien im Kontext der politischen und wirtschaftlichen Transformationen, Frankfurt am Main: Vervuert, Vols. 1-6, 2003.

International Telecommunication Union (ITU). World Telecommunication/ICT Development Report, Genebra: ITU, 2006.

JEHL, Douglas. The Internet’s ,Open Sesame’ Is Answered Warily, New York Times, 18.03.1999.

KÖßLER, Reinhart; MELBER, Henning. Chancen internationaler Zivilgesellschaft, Frankfurt am Main: Suhrkamp, 1993.

LIPSCHUTZ, Ronnie D. Reconstructing World Politics: The Emergence of Global Civil Society, Millenium: Journal of International Studies, n. 3, 1992, p. 389-420.

LUHMANN, Niklas. Protest: Systemtheorie und soziale Bewegungen, Frankfurt am Main: Suhrkamp, 1996.

MCLUHAN, Marshall; POWERS, Bruce. The Global Village: Transformations in World Life and Media in the 21st Century, Oxford: Oxford University Press, 1989.

PAULSON, Justin. About ‘¡Ya Basta!’ - www.ezln.org, rev. 19.11.1997, $<$ http://www.ezln.org/about.html> [acessado em 12.12.1997].

REDaktion (Orgs.). Chiapas und die Internationale der Hoffnung, Köln: ISP, 1997. 
RONFELDT, David; ARQUILLA, John. The Zapatista Social Netwar in Mexico, Santa Monica: RAND, 1998.

SASSEN, Saskia. Cyber-Segmentierungen: Elektronischer Raum und Macht. In: MÜNKE, Stefanr; ROESLER, Alexander (Orgs.). Mythos Internet, Frankfurt am Main: Suhrkamp, 1997.

SCHULZ, Markus S. Collective Action Across Borders: Opportunity Structures, Network Capacities, and Communicative Praxis in the Age of Advanced Globalization, Sociological Perspectives, V. 41, n. 3, 1998, p. 587-616.

SCHULZ, Markus S. Politische Gewalt in Mexiko. In: FISCHER, Thomas; KRENNERICH, MIchael (Orgs.). Politische Gewalt in Lateinamerika, Frankfurt am Main: Vervuert, 2000.

SCHULZ, Markus S. Mexiko zwischen Demokratisierung und Liberalisierung: Internet und Politik in Lateinamerika, V. 1, Frankfurt am Main: Vervuert, 2003.

TEUTHORN, Christina. From: Zapatistas, To: Öffentlichkeit, Subjekt: Revolution: Der Einfluß des Internet auf Konfliktprozesse am Beispiel des Chiapas-Konflikts, Diplomarbeit (Journ.), München: Ludwig-Maximilian-Universität München, 1999.

THOMPSON, John B. The Media and Modernity, Stanford, CA: Stanford University Press, 1995.

TOCQUEVILLE, Alexis de. Über die Demokratie in Amerika, Stuttgart: Reclam, ([1835/1840] 1997).

UNDP (United Nations Development Programme). Human Development Report 1999, New York: UNDP, 1999.

Virtual Sites. Virtual Sites Mission Statement, 1997.

$<$ http://www.v-site.net/vsi/mission.html> [acessado em 11.12.1997].

ZÜRN, Michael. Regieren jenseits des Nationalstaates, Frankfurt am Main: Suhrkamp, 1998. 